\title{
BMJ Open Effect of Human Development Index and other socioeconomic factors on mortality-to-incidence ratio of lips and oral cavity cancer in Mexican states: an ecological study
}

\author{
Edith Lara-Carrillo, ${ }^{1}$ Brenda Yuliana Herrera-Serna (D) ,2 \\ Gabriel Conzuelo-Rodríguez, ${ }^{3}$ Regiane Cristina do Amaral, ${ }^{4}$ \\ Raúl Alberto Aguilera-Eguía, ${ }^{5}$ Victor Hugo Toral-Rizo ${ }^{1}$
}

To cite: Lara-Carrillo $\mathrm{E}$, Herrera-Serna BY, ConzueloRodríguez G, et al. Effect of Human Development Index and other socioeconomic factors on mortality-to-incidence ratio of lips and oral cavity cancer in Mexican states: an ecological study. BMJ Open 2021;11:e042376. doi:10.1136/ bmjopen-2020-042376

- Prepublication history and additional supplemental material for this paper are available online. To view these files, please visit the journal online. To view these files, please visit the journal online (http://dx.doi org/10.1136/bmjopen-2020042376).

Received 04 July 2020 Accepted 20 April 2021

D) Check for updates

(c) Author(s) (or their employer(s)) 2021. Re-use permitted under CC BY-NC. No commercial re-use. See rights and permissions. Published by BMJ.

For numbered affiliations see end of article.

\section{Correspondence to} Dr Brenda Yuliana HerreraSerna;

bherrera@autonoma.edu.co

\section{ABSTRACT}

Objectives To assess the association between the Human Development Index (HDI) and covariates on the mortalityto-incidence ratio (MIR) of lips and oral cavity cancer (LOCC) in Mexico.

Design Ecological study.

Setting Data from 32 Mexican states for year 2019.

Participants Data set of male and female populations from Mexico.

Exposures Socioeconomic conditions based on HDI and covariates related to healthcare system capacity (total health spending per capita, school dropout and ratio of medical personnel in direct contact with patients).

Primary and secondary outcome measures MIR of LOCC by state and sex was calculated from the Global Burden of Disease Study website for year 2019. Data for calculating HDI 2019 by state and covariates were obtained from the National Institute of Statistics and Geography. A multiple regression model was constructed to measure the effects of $\mathrm{HDI}$ and covariates on LOCC-MIR. Results Among the states with the highest $\mathrm{HDI}(>0.780)$, Colima had the highest aged-standardised rates per 100.000 in men for incidence (5.026) and mortality (3.118). The greatest burden of the disease was found on men, with the highest Men:Women MIR in Colima (3.10) and Baja California Sur (2.73). The highest MIR $(>0.65)$ was found among the states with the lowest HDI (0axaca and Chiapas). For each unit of increase of the HDI there was a decrease in the LOCC- MIR of -0.778 , controlling for the covariates. The most suitable regression model explained the $57 \%(F(p): 0.000)$ of the variance. Conclusions Men were most affected by LOCC in Mexican states. The highest MIRs of LOCC were found in the states with the highest HDI. But a worse prognosis of the disease, expressed as a higher MIR, is expected in contexts with lower HDI in the country, even with lower MIRs.

\section{INTRODUCTION}

Cancer, as a cause of death in developed countries, ranks first, while it is the secondmost
Strengths and limitations of this study

- It is necessary to make lip and oral cavity cancer (LOCC) should receive attention given its high mortality when receiving a diagnosis, the differences between sexes and between populations, even within the same country.

- This study uses the latest data set from the Global Burden of Disease Study and a simple search strategy, which can be applied to continue monitoring changes in the incidence and uptake of mortality in Mexico.

- Although an association between socioeconomic conditions and the ratio of mortality-to-incidence due to LOCC was demonstrated, it is necessary to deepen the relationship of other variables to develop more complex models.

- More research is needed to strengthen survival data records as an ideal indicator.

cause in developing countries. ${ }^{12}$ Several factors, such as population ageing and growth, changes in lifestyles, economies and societies, are increasing the global burden of cancer, including those related to advances in human development. ${ }^{3}$ Therefore, as the lives of populations become more economically prosperous, the incidence of cancer commonly found in high-income populations (ie, breast, prostate, colorectal) increases. ${ }^{2}$

Lips and oral cavity cancer (LOCC) is a malignant neoplasm that affects the anterior parts of the tongue, the floor of the mouth, the lips, the hard palate, the oral mucous membrane, the gums and the retromolar area (International Statistical Classification of Diseases and Related Health Problems (ICD)-11 2B60-2B69). ${ }^{4}$ According to Global Cancer Observatory (GLOBOCAN), in 2020, 
there were 377713 new cases (age-standardised rate (ASR) 4.1) and 177757 deaths from this type of cancer (ASR 1.9). Men accounted for $69.95 \%$ of the incidence and $70.33 \%$ of mortality worldwide. ${ }^{5}$

The risk increases between $20 \%$ and $30 \%$ with individual tobacco or alcohol consumption, but the risk can be three times higher with combined use. ${ }^{6}$ There are other risk factors for specific subtypes: high-risk human papillomavirus (HPV) has been associated with cancers in the oropharyngeal regions (including the base of the tongue, the lingual tonsil and the soft palate) in subpopulations in selected countries, while lip cancers are strongly associated with ultraviolet radiation from exposure to sunlight. ${ }^{7}$

In the USA, LOCC accounts for approximately $5 \%$ of cancers, while in India, Brazil and Cuba it is among the five most common cancers, accounting for $25 \%-40 \%$ of all malignant neoplasms, and among the main causes of mortality among men. ${ }^{8}$ LOCC has a mortality of more than $50 \%$ of cases, an aspect that is highly influenced by the living conditions of the population, ${ }^{9}$ and access to quality and timely healthcare. ${ }^{10}$ In this sense, the mortality-to-incidence ratio (MIR) is an indicator of the results that a population can expect from a cancer diagnosis. High MIR values for a population are an indicator of poor cancer outcomes relative to incidence. ${ }^{11}$ Currently, the MIR can be calculated based on easily accessible and publicly used data on incidence and mortality according to the type of cancer in most countries, thanks to some initiatives such as the Global Burden of Disease Study, ${ }^{12}$ while survival data (considered to be superior to MIR) is publicly available only for limited databases covering a minimum of populations. Some studies have shown the severity and impact of cancer according to geographical regions using MIR, such as the states of a country. ${ }^{13-16}$

Although Mexico has not been among the countries with the highest rates of LOCG in the world ${ }^{17}$ or in the Latin American region, ${ }^{18}$ the different presence of the main known risk factors between the sexes, ${ }^{19}$ the latent influence of other factors of viral origin, ${ }^{20}$ and the constant changes in social conditions that have been reflected in widely applied indicators such as the Human Development Index (HDI), ${ }^{21-23}$ make it relevant to know how these associations have been according to the most recent data available. To our knowledge, LOCC has not been studied at the state level and by sex in Mexico.

The objective of this study was to construct and compare MIR at the state level to assess geographical disparities in survival of LOCG in Mexico. State MIRs were also stratified by sex, and indicators such as HDI, total health spending per capita, school dropouts and the proportion of medical personnel in direct contact with the patient per 1000 inhabitants were included to further explore the existing disparities.

\section{MATERIALS AND METHODS}

This ecological study used data from the Global Burden of Disease (GBD) for LOCC. ${ }^{12}$ The GBD is a global initiative that records historical information on demographics and health of the different countries of the world; for some countries it has subnational information. Data were retrieved on ASRs per 100000 inhabitants for the incidence and mortality of LOCC by sex and for each state of Mexico for the year 2019. The strategy for data extraction from the GBD results tool ${ }^{12}$ included: incidence and deaths; age-standardised prevalence; year 2019; neoplasm of the oral cavity and lips; causality; each of the 32 Mexican states; men and women; and rates.

To obtain the HDI for each of the 32 states of Mexico, data from the National Institute of Statistics and Geography was used through the Index Calculation tool using Excel from the United Nations Development Programme. ${ }^{24}$

\section{Patient and public involvement statement}

Since it is an ecological study, the design is based on secondary data and no patients participated in the development of the investigation.

\section{Ethics approval statement}

As the study was considered risk-free, it was not submitted to any ethics committee. This study complies with the Guidelines for Accurate and Transparent Health Estimates Reporting recommendations. ${ }^{25}$

\section{Outcome variable: MIR of LOCC}

The MIR is an indirect measure of cancer survival and is calculated by dividing the age-standardised death rate by the age-standardised incidence rate. The MIR was estimated for each of the 32 states of Mexico. The continuous version of this measure was used as the dependent variable, as reported by Khazaei $e t a l .^{26-28}$

\section{Predictor variable: HDI}

The HDI is a summary measure of achievement in three key dimensions of human development: health, education and standard of living. It is calculated from two steps: first, the minimum and maximum values are determined (considered as 'natural zeros' and 'possible goals', respectively), to generate the indices between 0 and 1 . Second, the index of each dimension and then the geometric mean of the three indices is generated, the education dimension has two categories. ${ }^{29}$ The established values and the formula are shown in table 1.

The HDI reports maintain the same cut-off points in the HDI for the grouping of countries that were introduced in 2014. Report: low (HDI <0.550); medium $(0.550$ $<$ HDI $<0.699)$; high $(0.700<\mathrm{HDI}<0.799)$; very high (HDI $>0.800$ ). The HDI measures were calculated for each of the 32 states of Mexico for 2019 using the Excel tool of the United Nations Development Programme, ${ }^{24}$ which has the mathematical formulas. 
Table 1 Values and formula for calculating the Human Development Index

\begin{tabular}{llcc}
\hline Dimension & Indicator & Minimum & Maximum \\
\hline Health & $\begin{array}{l}\text { Life expectancy } \\
\text { (years) }\end{array}$ & 20 & 85 \\
Education & $\begin{array}{l}\text { Expected years of } \\
\text { schooling (years) }\end{array}$ & 0 & 18 \\
& $\begin{array}{l}\text { Mean years of } \\
\text { schooling (years) }\end{array}$ & 0 & 15 \\
$\begin{array}{l}\text { Standard of } \\
\text { living }\end{array}$ & $\begin{array}{l}\text { GNI per capita } \\
(2017 \text { PPP\$) } \\
\text { HDI }=\left(\mathbf{I}_{\text {Health }}{ }^{*} \mathbf{I}_{\text {Education }}{ }^{\mathbf{I}_{\text {Income }}}\right.\end{array}$ & 100 & 75000 \\
\hline
\end{tabular}

Source: Human Development Indices and Indicators: 2020. ${ }^{29}$

The asterisk implies that the three indices are multiplied.

GNI, Gross National Income; HDI, Human Development Index; PPP,

Purchasing Power Parity.

\section{Covariates}

Total expenditure on health per capita

The data collected integrate public and private health spending per capita in each Mexican state. Quantifying the relationship between health spending and outcomes provides important evidence on the efficiency of the health system. Additionally, this quantification provides an opportunity to take action with respect to national health policy to address health inequalities. In the long term, continuous evaluation of the dynamics of this relationship can also provide useful mechanisms for evaluating the degree of success of changes in national health policy and the overall performance of the health system. ${ }^{30}$ The data were obtained from the Centre for Economic and Budgetary Research. ${ }^{31}$

\section{School dropout}

According to the 2016 HDI report, ${ }^{32}$ it is recommended to complement the enrolment and schooling data with dropout rates. This is because multiple factors reduce school enrolment and attendance. Examples of such factors are nutritional deficiency, personal and social problems, and even the need to start work at an early age. Therefore, the situation becomes a relevant factor to consider and evaluate. ${ }^{32}$ Dropout rates were used for all educational levels and states in 2019. Dropout rates are calculated by subtracting the number of students enrolled at each level from the projections made year by year from those who should enter each school year. ${ }^{33}$ Data were obtained from the Institute for the Evaluation of Education. ${ }^{34}$

\section{Primary care medical and dental practitioners}

Since the survival of LOCC is largely based on the delay and stage of diagnosis of patients who are referred by primary care physicians and dentists, the effect of referral by one or the other has been studied. A recent systematic review found that the percentage of medical referrals ranged from $13 \%$ to $86 \%$ and the referrals of the dentists ranged between $15 \%$ and $80 \%$ without statistical significance between the remission of one or the other on the results in the patients. ${ }^{35}$ The present study considered the number of graduated dentists and the ratio of medical personnel in direct contact with the patient per 1000 inhabitants for the year 2019 in each of the states. The data were obtained from the National Association of Universities and Institutions of Higher Education ${ }^{36}$ and the Secretariat of Health of Mexico, ${ }^{37}$ respectively.

\section{Analysis}

Apart from the study variables, the population of each Mexican state for the year 2019 was considered (table 2). Histograms and kernel density plots were used to analyse the outcome variable (LOCC MIR) and the main predictor (HDI). Both had an approximately normal distribution (online supplemental appendix 1).

Simple linear regression models were run to analyse the individual contribution of each predictor to LOCC MIR. The coefficient of determination (r2) was used to compare the models and it was assumed that an independent variable significantly predicted the MIR if its $p$ value was $<0.05$ (F test). In this step, the number of graduated dentists in each of the states (r2: 0.006, $\mathrm{p}$ value $=0.668$ ) was eliminated (table 3).

Finally, a multiple regression model was used to evaluate the association between LOCC-MIR and a combination of the outcome variables. Eight models were analysed. All models included HDI as a minimal predictor, and the final model included MIR, HDI and three other covariates. All analysis was done in Stata V.15.1.

\section{RESULTS}

In general, the ASR of incidence in Mexico is 2247 for men and 1301 for women, while mortality is 1388 and 0.749 , respectively. This resulted in a higher MIR in men (0.619) than in women (0.575). Table 2 shows the ASR by age of incidence and mortality, and the MIR of LOCC together with the HDI indicators, total health expenditure, school dropout and ratio of medical personnel in direct contact with the patient per 1000 inhabitants.

The states with the highest HDI are those with the highest incidence rates. The average HDI for Mexico is 0.772; with the highest value in Mexico City (very high HDI: 0.885) and the lowest in Chiapas (high HDI: 0.700). The highest MIR among men can be seen in the states of Chiapas (0.664) and Guerrero (0.659); the last two are the states with the lowest HDI in the country. Interestingly, Colima's incidence rates (ASR 50.26) and mortality (ASR 3.118) among men stand out compared with the rest of the country. It also has one of the highest incidence rates among women (ASR 1624); only surpassed by the Veracruz rate (ASR 1629).

Among the covariates, the highest health expenditure per capita is found in Mexico City (MXN11 251); which implies an important difference compared with the state with the lowest health expenditure (Chiapas: MXN3386). Michoacán de Ocampo has the highest dropout rate 


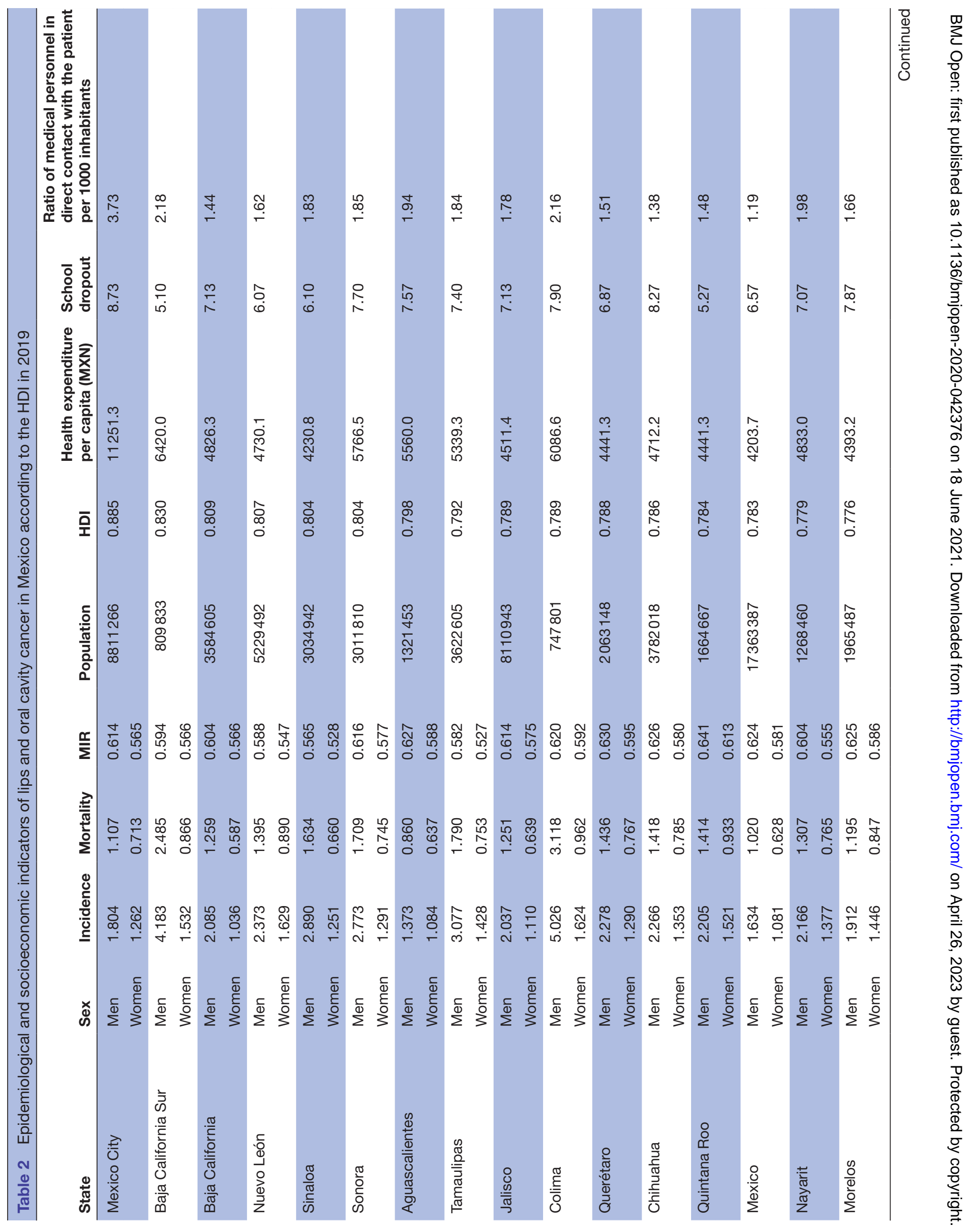




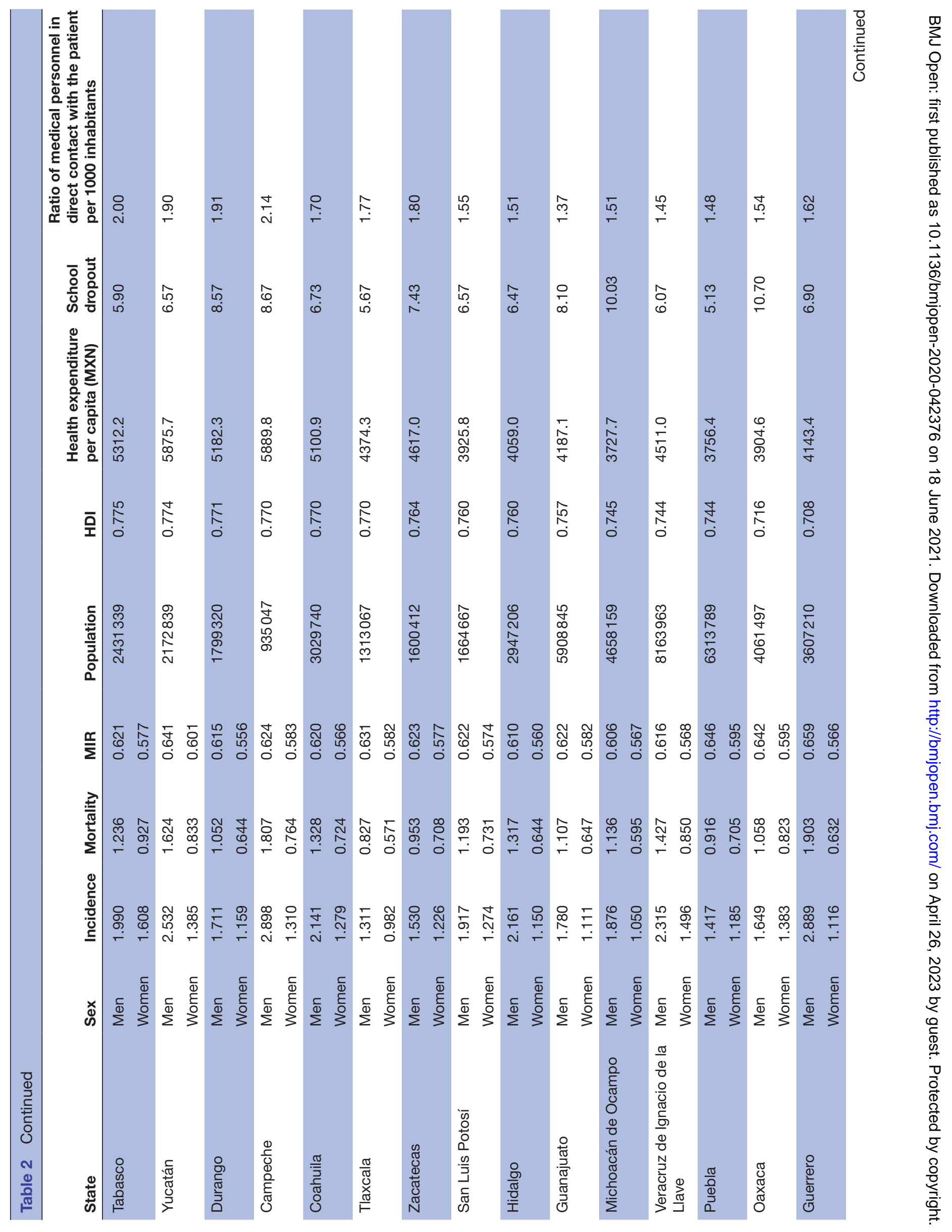




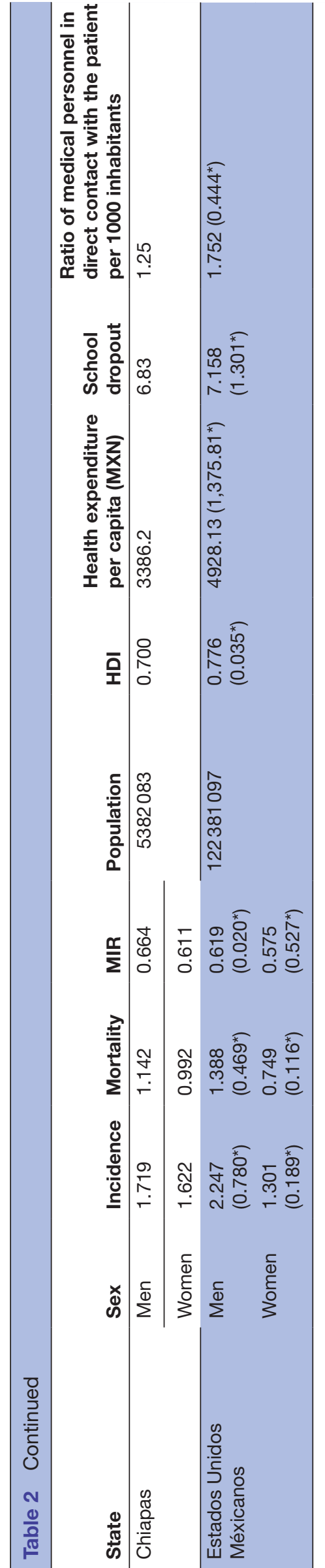

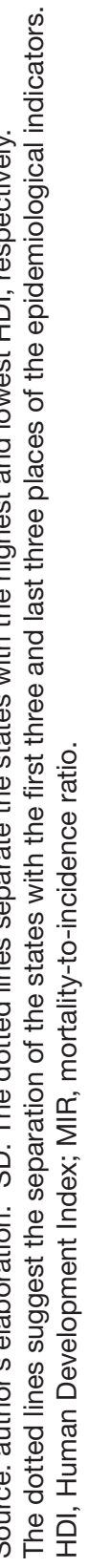

(10.47) and Mexico City has the highest proportion of medical personnel in direct contact with the patient per 1000 inhabitants (3.73).

Linear regression models showed that four of the five study variables were statistically significant $(p<0.05)$. A modest proportion of the total variability is explained by the HDI alone $(\mathrm{r} 2=0.346)$. Other results of simple linear models are shown in table 3.

The final model was chosen using a combination of the coefficient of variability (r2) together with the Akaike and Bayesian information criteria (online supplemental appendix A). The model with greater parsimony was preferred to the others. The final multivariate model, which included the HDI and the other three covariates as exposure variables, showed that the proportion of variability in the LOCC MIR explained by the predictors was $57.01 \%$. In addition, the variance inflation factor with a threshold of 10 was used to assess collinearity (online supplemental appendix A). The fit of the model appears strong with most of the points close to the prediction line (figure 1). Other tests applied to the final model are shown in online supplemental appendix A.

In general, whenever the HDI increases there is a corresponding decrease of -0.778 units in the LOCG MIR while controlling for total health spending per capita, school dropouts and the proportion of medical personnel; the behaviour of the HDI rates and MIR is statistically significant (table 4). Therefore, the total variability explained by the model was moderate with around $57.01 \%$

\section{DISCUSSION}

This study highlights the utility of using incidence, mortality and MIR to describe variations in cancer distribution and survival between and within states for populations and sexes. Although the highest incidence and mortality rates of LOCC were observed in states with a high HDI, calculation and comparison of MIR at the state level for LOCC revealed that some states with a lower HDI have relatively low survival rates of LOCG compared with other central and northern states. Indicators such as the HDI and the covariates used gave a moderate explanation of the possible results of a diagnosis of LOCC. Despite the fact that Mexico is a country with low rates of LOCC, these type of data provide relevant information for various areas of society to explore in-depth the determinants of these differences in mortality versus incidence, and identify actions that allow a reduction of the cancer burden in high mortality settings. To our knowledge, this is the first research in Mexico that studies the relationship between socioeconomic factors and LOCC in the 32 states.

We found that men are more affected by LOCG than women, as observed in other Latin-American contexts, reaching a male/female ratio of $>4.0$ in Paraguay. ${ }^{18}$ This fact has been related to the higher prevalence in men who present with the main traditional risk factors such as tobacco and alcohol consumption. ${ }^{38}$ 
Table 3 Regression models between mortality-to-incidence ratio and each predictor

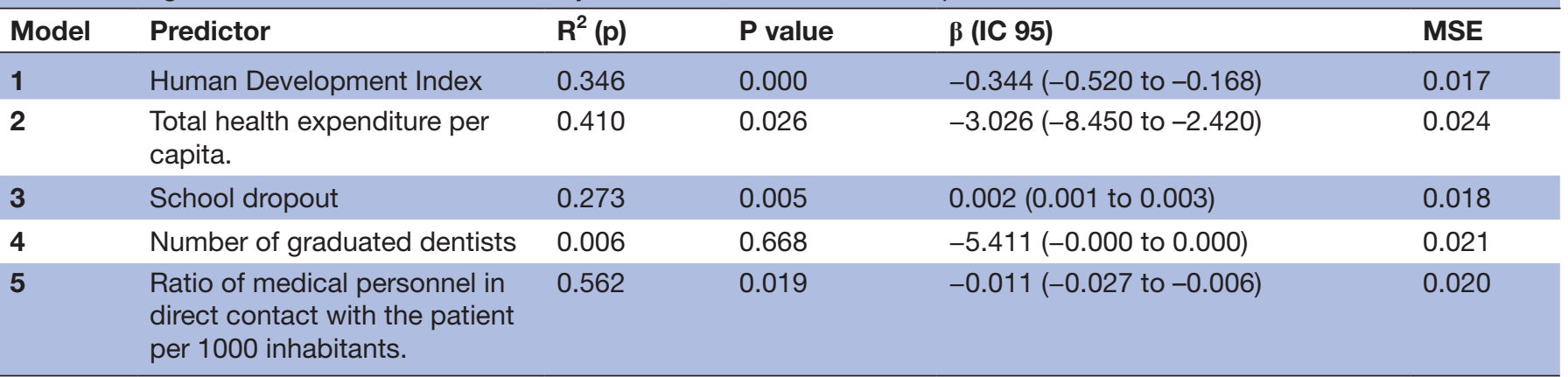

Source: author's elaboration.

MSE, Mean Squared Error; $p, p$ value; $r 2, r$ squared value.

In the study by Reynales-Shigematsu et $a l^{39}$ evaluating the effects of tobacco control policies on smoking in Mexico, the authors found that smoking rates have been reduced by approximately $30 \%$ as a result of policies such as cigarette taxes, open air smoke laws, media campaigns, advertising, prohibitions, warning labels, treatment cessation and tobacco access policies for young people, implemented since 2002. However, the implementation of the recommendations to control tobacco use suggested by the MPOWER agreement has progressed unevenly in Mexican states, according to the 2016 National Survey on Drug, Alcohol and Tobacco Consumption Encuesta Nacional de Consumo de Drogas, Alcohol y Tabaco; in spanish (ENCODAT) ${ }^{40}$

Among the 32 states, those with the highest MIRs among men were Colima, Baja California Sur, Tamaulipas, Guerrero and Campeche. Among these states, only Baja California Sur showed a higher prevalence of smoking in men

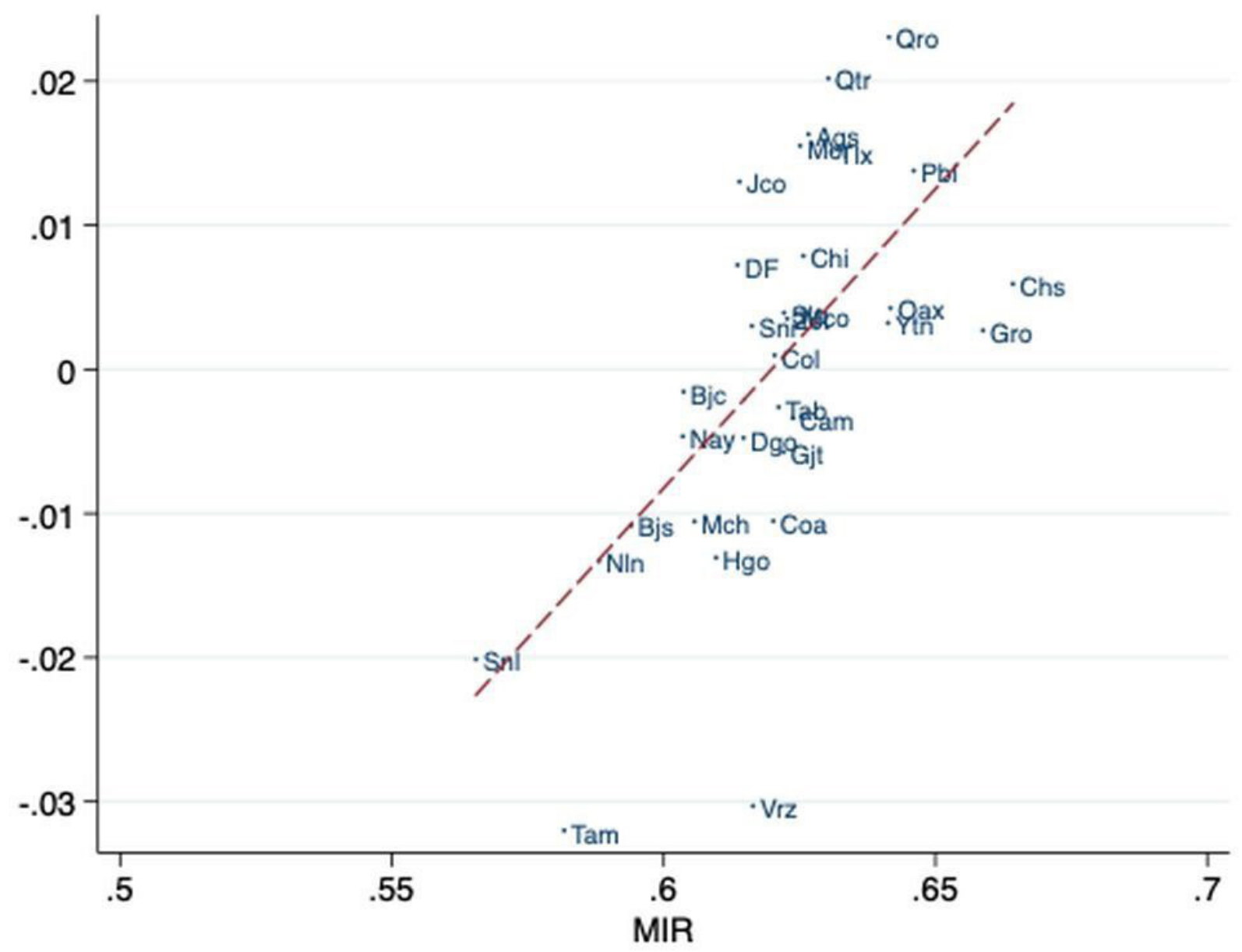

Figure 1 Mortality-to-incidence ratio: observed versus predicted values. Source: author's elaboration. 


\begin{tabular}{|c|c|c|}
\hline p: 0.0001 & $R^{2}: 0.5701$ & Adj $R^{2}: 0.5064$ \\
\hline Human Development Index & $-0.778(-1.159$ to 0.396$)$ & 0.000 \\
\hline Total health expenditure per capita & $0.000(7.945$ to 0.000$)$ & 0.003 \\
\hline
\end{tabular}

Source: author's elaboration.

The bold refers only to style and the format defined by the magazine can be used $\mathrm{p}, \mathrm{p}$ value; $\mathrm{r} 2, \mathrm{r}$ squared value.

(29.8\% for men and $10.1 \%$ for women) than the national prevalence $(27.1 \%$ for men and $8.7 \%$ for women). This contrasts with the states with the highest prevalence of smoking such as Mexico City (42.3\% in men; $20.0 \%$ in women) and other northern states, ${ }^{40}$ which are also the states with the greatest economic development. ${ }^{41}$ Worldwide in 2015, the age-standardised prevalence of daily smoking was $25.0 \%$ (95\% uncertainty interval (UI) $24.2 \%$ to $25.7 \%$ ) in men and $5.4 \%$ (95\% CI $5.1 \%$ to $5.7 \%$ ) in women. Among men, the prevalence of smoking was highest in countries with a medium Sociodemographic Index (SDI), while for women, countries with a high SDI had the highest prevalence of smokers. ${ }^{42}$

ENCODAT $^{40}$ showed that excessive alcohol consumption occurred in $19.8 \%$ of the population; $10.9 \%$ men and $8.9 \%$ women. The regions that presented excessive alcohol consumption, above the national average $(19.8 \%)$ were the north-west and west, ${ }^{40}$ to which Baja California Sur and Colima belong, respectively. Alcohol consumption has increased in Mexico among women (mainly among the youngest), mainly in border regions. ${ }^{43}$ Globally, in 2016, 25\% (95\% UI 23\% to 27\%) of women were current drinkers, as were $39 \%^{36-43}$ of men. The prevalence was highest for high SDI settings, where $72 \%(95 \%$ IU $69 \%$ to $75 \%)$ of women and $83 \%(80 \%$ to $85 \%)$ of men were current drinkers. The prevalence of alcohol consumption was lower in places with low to medium SDI, where $8.9 \%(95 \%$ UI $6.6 \%$ to $9.7 \%)$ of women and $20 \%^{17-22}$ of men were current drinkers. Across all SDI quintiles, women consumed less alcohol than men, and the size of this disparity decreased with higher SDI levels. ${ }^{44}$

The epidemiological behaviour of LOCC has shown changes. Although it still occurs in populations with the presence of known risk factors such as tobacco and alcohol consumption, this is no longer sufficient to explain its higher prevalence in countries such as India, France or Brazil. ${ }^{45}$ The prevalence of tobacco and alcohol use in the world as a whole has decreased, especially in men. ${ }^{42}$ But not so the prevalence of LOCC accompanied by a decrease in the ages of onset and an increase in the prevalence of oral cancer in the youngest population ( $<45$ years) worldwide, particularly in Western populations. ${ }^{46}$ Thus, it has been sensitised to study other aetiological factors such as the role of HPV,${ }^{47}$ immunodeficiency ${ }^{48}$ and predisposition to genetic instability. ${ }^{49}$

Although the evidence supporting that HPV is a causative agent of LOCC is controversial, a positive association has been observed between HPV and potentially malignant lesions that develop squamous cell carcinoma in the oral cavity, reaching an OR of $3.97 .^{50}$ Subtype 16 has been associated with $>90 \%$ of HPV-LOCC cases. ${ }^{6}$ The profile of patients who develop LOCG associated with HPV is predominantly men, between 40 years and 55 years old, especially white, with a high educational and socioeconomic level, with sexual behaviours considered high risk, not necessarily smokers or drinkers. Globally, the prevalence of HPV is between $9 \%$ and $13 \%$, with geographical differences and a greater participation in developing countries. A study in Mexico showed a prevalence of oral HPV infection of $12.1 \% .^{51}$ Unfortunately, the absence of data by state makes it difficult to incorporate this variable in this type of study at this time. However, prophylactic vaccines may be useful in the prevention of squamous cell carcinoma of the oral cavity associated with HPV, but prospective studies on this topic are lacking. ${ }^{52}$

Baja California and Colima share other characteristics: as tourist sites close to the USA, they have high national immigration ( $>9 \%$ of the national population, most of them under 5 years of age) above the national average of 2.9\%; high international migration ( $>6 \%$ of the national population, the majority under 5 years of age) above the national average of $3.5 \%{ }^{53}$ changes in demographic composition with a thickening in the middle of the pyramid; ${ }^{53}$ an apparent increase in the incidence and mortality from cancers in men who are severely affected by the so-called 'Western lifestyle' (ie, colorectal, lung and prostate cancers) ${ }^{12}$ and high development according to our findings (HDI $>0.785)$. Some studies have shown a positive relationship between the incidence of breast $^{54}$ and prostate ${ }^{55}$ cancers and the HDI, while the relationship with mortality has been negative. ${ }^{545}$ This has been associated with greater possibilities for proper registration, diagnosis and treatment, as well as changes in the regular patterns of presentation of the disease in relation to socioeconomic conditions.

It has been assumed that people can migrate from less developed to more industrialised places, as an example of the theory of a 'rapid epidemiological transition', so 
that they move between contexts that are at different stages of the epidemiological transition. ${ }^{56}$ This type of transit is common between Mexico and the USA, especially in the northern states of Mexico. Therefore, although at the place of birth the causes of mortality are related to infections, at the place of destination mortality may be lower and related to lifestyle. Examples of the latter are diabetes, cardiovascular disease and some cancers, which become increasingly common with longer stays and among migrant children. ${ }^{57}$ In fact, countries with very high and high HDI account for $41 \%$ of cancer cases in the world. ${ }^{2}$ Among the most common types of cancer are those of the lung, stomach, colorectal, prostate and breast; all have shown a negative relationship between their MIR and the HDI. ${ }^{58}$ In agreement, mortality from LOCG has been associated with the HDI in Asia $\left(\mathrm{r}^{2}:-0.66, \mathrm{p}<0.001\right)^{21}$ and in the world $\left(\mathrm{r}^{2}:-0.29, \mathrm{p}<0.05\right) .{ }^{59}$

The MIR is a relatively crude measure of cancer outcomes. A more robust measure might include survival; however, survival data are only available in some specialised centres in the country, which do not collect the national population, ${ }^{60}$ and exclude the territories where the most significant deficiencies in socioeconomic conditions were identified in relation to the indicators studied. As such, we feel that this loss of granularity would result in an underpowered data set to support regression analyses. Mexico's MIRs for LOCC (0.619 for men and 0.575 for women) are higher than those of Asia (0.533 for men and 0.548 for women), Latin America and the Caribbean ( 0.444 for men and 0.374 for women) and North America (0.178 for men and 0.198 for women). ${ }^{5}$ The Mexican states with the highest MIR in men were Chiapas (0.664) and Guerrero (0.659), which is similar to Sri Lanka $(0.667)$ as a country with a high HDI. ${ }^{5}$ Although the incidence and mortality were higher in other states, with higher HDI and higher prevalence of some risk factors, as has been explained, a relatively high MIR reflects poorer chances of survival, even in the presence of lower incidence. In essence, less developed states may have less access to quality health care. A relatively high MIR in some contexts reflects health-system limitations, especially in the diagnosis and management of cancer, such as an unavailability of adequate treatment that includes primary and specialised health personnel, sophisticated surgeries and chemotherapy regimens. ${ }^{10}$ This can be seen in the fact that Chiapas and Guerrero are the states with the lowest health expenditure per capita $(<$ MXN3900) and both have a ratio of medical personnel in direct contact with the patient per 1000 inhabitants under the national mean ( $<1.50$ vs 1.75 national). In many settings, MIRs have been increasingly used to assess the efficacy of cancer control programmes within,${ }^{61}$ and between, countries. ${ }^{62}$ It can highlight disparities in access and acceptance of treatment, as well as in detection and prevention practices, reflecting the need to strengthen timely access to health services within states to generate effective prevention of LOCC, early diagnosis and avoiding the poor prognosis associated with the disease, limited quality of services and delays in care.

For its part, the study of socioeconomic indicators has shown that economic growth does not reach the entire population in an equitable manner and that it does not necessarily lead to human development. This is especially true when evaluating HDI ${ }^{63}$ which showed minimal differences between Mexican states. In general, among the states of Mexico and the world, the main advances in HDI have been due to the increase in life expectancy at birth, especially as a result of important policies sustained over time that fight against maternal and infant mortality. ${ }^{63}$ Worldwide, in 2019, life expectancy for women was 83.9 years and 78.3 years for men; while in Mexico it was 78.5 years for women and 76.2 years for men. ${ }^{12}$ This reflects the possibility of suffering from diseases such as LOCC with cumulative exposure to multiple risk factors, beginning at a younger age.

Our study has several limitations in addition to those inherent to ecological designs, which do not allow us to speak of causality but of association. Many low-income and middle-income countries have cancer registries and vital registry data with limitations for analysis. Estimates in Mexico depend on multiple sources of information in the absence of country-specific epidemiological data on cancer incidence and mortality. Additionally, the quality of data from vital registration systems and cancer registries may vary from state to state, with under-reporting or miscoding of cancer cases or deaths. In this sense, through the redistribution of undefined codes and other estimation analyses, the GBD methodology ${ }^{64} 65$ tries to correct the problems of quality and comparability of the data, at the national and subnational levels. Some registry efforts, such as the National Cancer Registry Network, ${ }^{60}$ allow data from populations with limitations to continue to be considered in their registries given their proximity to places with more robust data. Our findings allow us to know the national needs for LOCC according to the observed rates.

The data analysed suggest that LOCC-MIR is inversely related to the HDI, total health spending per capita, school dropouts and the proportion of medical personnel, by up to $57 \%$. Hence, the increase in HDI, and the other indicators, triggers the possibility of reducing mortality due to LOCC compared with cases of incidence.

\section{Author affiliations \\ ${ }^{1}$ Universidad Autónoma del Estado de México, Toluca, México, Mexico \\ ${ }^{2}$ Departamento de Salud Oral, Universidad Autónoma de Manizales, Manizales, Colombia \\ ${ }^{3}$ University of Pittsburgh, Pittsburgh, Pennsylvania, USA \\ ${ }^{4}$ Departamento de Odontologia, Universidade Federal de Sergipe, Aracajú, Sergipe, Brazil \\ ${ }^{5}$ Departamento de Salud Pública, Facultad de Medicina, Carrera de Kinesiología, Universidad Católica de la Santísima Concepción, Concepción, Chile}

Contributors EL-C: conceptualisation, project administration. BYH-S: investigation, writing the original draft. GC-R: methodology, formal analysis. RCdA: visualisation, formal analysis, supervision. RAA-E: review and editing, visualisation. VHT-R: writing, review and editing. 
Funding The authors have not declared a specific grant for this research from any funding agency in the public, commercial or not-for-profit sectors.

Competing interests None declared.

Patient consent for publication Not required

Ethics approval The framework project was known and approved by the Secretariat for Advanced Studies of the Autonomous University of the State of Mexico (registration number DOCCSA-0618 March 2018).

Provenance and peer review Not commissioned; externally peer reviewed.

Data availability statement All data relevant to the study are included in the article or uploaded as supplementary information and additional information is not available.

Supplemental material This content has been supplied by the author(s). It has not been vetted by BMJ Publishing Group Limited (BMJ) and may not have been peer-reviewed. Any opinions or recommendations discussed are solely those of the author(s) and are not endorsed by BMJ. BMJ disclaims all liability and responsibility arising from any reliance placed on the content. Where the content includes any translated material, BMJ does not warrant the accuracy and reliability of the translations (including but not limited to local regulations, clinical guidelines, terminology, drug names and drug dosages), and is not responsible for any error and/or omissions arising from translation and adaptation or otherwise.

Open access This is an open access article distributed in accordance with the Creative Commons Attribution Non Commercial (CC BY-NC 4.0) license, which permits others to distribute, remix, adapt, build upon this work non-commercially, and license their derivative works on different terms, provided the original work is properly cited, appropriate credit is given, any changes made indicated, and the use is non-commercial. See: http://creativecommons.org/licenses/by-nc/4.0/.

ORCID iD

Brenda Yuliana Herrera-Serna http://orcid.org/0000-0002-3347-2069

\section{REFERENCES}

1 Bray F, Ferlay J, Soerjomataram I, et al. Global cancer statistics 2018: GLOBOCAN estimates of incidence and mortality worldwide for 36 cancers in 185 countries. CA Cancer J Clin 2018;68:394-424.

2 Fidler MM, Bray F, Soerjomataram I. The global cancer burden and human development: a review. Scand J Public Health 2018;46:27-36.

3 Fidler MM, Soerjomataram I, Bray F. A global view on cancer incidence and national levels of the human development index. Int $J$ Cancer 2016;139:2436-46.

4 World Health Organization. International classification of diseases, 11th revision (ICD-11). Geneva, Switerland, 2018.

5 GLOBOCAN. Cancer incidence, mortality and prevalence worldwide. [Internet]. cancer observatory, 2020. Available: https://gco.iarc.fr/ today/home

6 Noble DJ, Jefferies SJ. Squamous cell carcinoma of the oral cavity, oropharynx and upper oesophagus. Medicine 2019;47:269-74.

7 Miranda-Filho A, Bray F. Global patterns and trends in cancers of the lip, tongue and mouth. Oral Oncol 2020;102:104551.

8 Cohen N, Fedewa S, Chen AY. Epidemiology and demographics of the head and neck cancer population. Oral Maxillofac Surg Clin North Am 2018;30:381-95.

9 Ribeiro ILA, de Medeiros JJ, Rodrigues LV, et al. Factors associated with lip and oral cavity cancer. Rev Bras Epidemiol 2015;18:618-29.

10 Gigliotti J, Madathil S, Makhoul N. Delays in oral cavity cancer. Int J Oral Maxillofac Surg 2019;48:1131-7.

11 Odahowski CL, Hébert JR, Eberth JM. Regional variation in lung and bronchus cancer survival in the US using mortality-to-incidence ratios. Spat Spatiotemporal Epidemiol 2018;26:107-12.

12 University of Washington. Institute for health metrics and evaluation. [Internet]. GBD results tool, 2020. Available: http://ghdx.healthdata. org/gbd-results-tool

13 Mousa AG, Bishr MK, Mula-Hussain L, et al. Is economic status the main determinant of radiation therapy availability? the Arab world as an example of developing countries. Radiother Oncol 2019;140:182-9.

14 Bogani G, Lopez S, Mantiero M, et al. Immunotherapy for platinumresistant ovarian cancer. Gynecol Oncol 2020;158:484-8.

15 Dy GW, Gore JL, Forouzanfar MH, et al. Global burden of urologic cancers, 1990-2013. Eur Urol 2017;71:437-46.

16 Bishr MK, Zaghloul MS. Radiation therapy availability in Africa and Latin America: two models of low and middle income countries. Int $J$ Radiat Oncol Biol Phys 2018;102:490-8.
17 Ren Z-H, Hu C-Y, He H-R, et al. Global and regional burdens of oral cancer from 1990 to 2017: results from the global burden of disease study. Cancer Commun 2020;40:81-92

18 Herrera-Serna BY, Lara-Carrillo E, Toral-Rizo VH, et al. Relationship between the human development index and its components with ora cancer in Latin America. J Epidemiol Glob Health 2019;9:223-32.

19 Herrera-Serna B, Lara-Carrillo E, Toral-Rizo V. Efecto de las políticas de control de factores de riesgo sobre La mortalidad POR cáncer oral en América Latina. Rev Esp Salud Pública 2019;93.

20 Tam S, Fu S, Xu L, et al. The epidemiology of oral human papillomavirus infection in healthy populations: a systematic review and meta-analysis. Oral Oncol 2018;82:91-9.

21 Tiyuri A, Mohammadian-Hafshejani A, Iziy E, et al. The incidence and mortality of lip and oral cavity cancer and its relationship to the 2012 human development index of Asia. Biomed. Res. Ther. 2017;4:1147-65

22 Greiman AK, Rosoff JS, Prasad SM. Association of human development index with global bladder, kidney, prostate and testis cancer incidence and mortality. BJU Int 2017;120:799-807.

23 Shao S-Y, Hu Q-D, Wang M, et al. Impact of national human development index on liver cancer outcomes: transition from 2008 to 2018. World J Gastroenterol 2019;25:4749-63.

24 United Nations Development Programme. Human development reports [Internet]. documentarion an resources: caluculating de indices, 2020. Available: http://hdr.undp.org/en/content/calculatingindices

25 Stevens GA, Alkema L, Black RE, et al. Guidelines for accurate and transparent health estimates reporting: the gather statement. Lancet 2016;388:e19-23.

26 Khazaei S, Rezaeian S, Soheylizad M, et al. Global incidence and mortality rates of stomach cancer and the human development index: an ecological study. Asian Pac J Cancer Prev 2016;17:1701-4.

27 Khazaei S, Rezaeian S, Ayubi E, et al. Global prostate cancer incidence and mortality rates according to the human development index. Asian Pac J Cancer Prev 2016;17:3793-6.

28 Khazaei S, Rezaeian S, Khazaei S, et al. Effects of human development index and its components on colorectal cancer incidence and mortality: a global ecological study. Asian Pac J Cancer Prev 2016;17:253-6.

29 United Nations Development Programme. Human development index, technical notes. Washington DC, 2020.

30 Edney LC, Haji Ali Afzali H, Cheng TC, et al. Mortality reductions from marginal increases in public spending on health. Health Policy 2018;122:892-9.

31 et alGurusamy V, Jimenez-Sanchez L, Jaramillo-Villanueva JL. Estructura del ingreso y consumo de hogares rurales en diferentes regiones agro-económicas de Puebla, México. Agric Soc y Desarro [Internet], 2018. Available: www.scielo.org.mx/scielo.php?script=sci arttext\&pid=S1870-54722018000200215\&lng=es\&tlng=es

32 United Nations for Develpment Programme. Human Develpment report, human development for everyone, 2016.

33 Instituto Nacional para la Evaluación de la Educación. Panorama educativo de México. Indicadores del Sistema Educativo Nacional 2017. Educación básica Y media superior. Ciudad de México, 2017.

34 Instituto Nacional para la Evaluación de la Educación. La educación obligatoria en México. Informe 2019. Ciudad de México 2019.

35 Langton S, Cousin GCS, Plüddemann A, et al. Comparison of primary care doctors and dentists in the referral of oral cancer: a systematic review. Br J Oral Maxillofac Surg 2020;58:898-917.

36 National Association of Universities and Institutions of Higher Education [Internet], 2020. Available: http://www.anuies.mx/

37 Gobierno de México. Secretaría de salud de México [Internet]. Datos abiertos, 2020. Available: https://www.gob.mx/salud/ documentos/datos-abiertos-bases-historicas-direccion-general-deepidemiologia?idiom $=$ es

38 Gupta B, Bray F, Kumar N, et al. Associations between oral hygiene habits, diet, tobacco and alcohol and risk of oral cancer: a casecontrol study from India. Cancer Epidemiol 2017;51:7-14.

39 Reynales-Shigematsu LM, Fleischer NL, Thrasher JF, et al. Effects of tobacco control policies on smoking prevalence and tobaccoattributable deaths in Mexico: the SimSmoke model. Rev Panam Salud Publica 2015;38:316-25.

40 México Gde. Encuesta nacional de consumo de drogas, alcohol Y tabaco 2016-2017. Ciudad de México, 2017.

41 Programa de las Naciones Unidas para El Desarrollo. Índice de Desarrollo Humano para Las entidades federativas, México: Avance continuo, diferencias persistentes. México, 2015

42 GBD 2015 Tobacco Collaborators. Smoking prevalence and attributable disease burden in 195 countries and territories, 19902015: a systematic analysis from the global burden of disease study 2015. Lancet 2017;389:1885-906. 
43 Orozco R, Benjet C, Ruiz Velasco-Acosta S, et al. Area-level disadvantage and alcohol use disorder in northern Mexico. Drug Alcohol Depend 2017;175:219-26.

44 Griswold M, Fullman N, Hawley C, et al. Alcohol use and burden for 195 countries and territories, 1990-2016: a systematic analysis for the global burden of disease study 2016. Lancet 2018;392:1015-35.

45 Rahman Q, locca O, Kufta K. Global burden of head and neck cancer. Oral Maxillofac Surg Clin N Am 2020;4:1-9.

46 Hussein AA, Helder MN, de Visscher JG, et al. Global incidence of oral and oropharynx cancer in patients younger than 45 years versus older patients: A systematic review. Eur J Cancer 2017;82:115-27.

47 Krüger M, Pabst AM, Walter C, et al. The prevalence of human papilloma virus (HPV) infections in oral squamous cell carcinomas: a retrospective analysis of 88 patients and literature overview. J Craniomaxillofac Surg 2014:42:1506-14.

48 Chi AC, Day TA, Neville BW. Oral cavity and oropharyngeal squamous cell carcinoma--an update. CA Cancer J Clin 2015;65:401-21.

49 González-Ramírez I, Soto-Reyes E, Sánchez-Pérez Y, et al. Histones and long non-coding RNAs: the new insights of epigenetic deregulation involved in oral cancer. Oral Oncol 2014;50:691-5.

50 de Abreu PM, Có ACG, Azevedo PL, et al. Frequency of HPV in oral cavity squamous cell carcinoma. BMC Cancer 2018;18:1-8.

51 de la Garza-Ramos MA, Urrutia-Baca VH, Urbina-Rios CS, et al. Prevalence of human papillomavirus in the oral cavity of an Indigenous community from Southwest México. Infect Genet Evol 2020;83:104283.

52 Abbas KM, van Zandvoort K, Brisson M, et al. Effects of updated demography, disability weights, and cervical cancer burden on estimates of human papillomavirus vaccination impact at the global, regional, and national levels: a prime modelling study. Lancet Glob Health 2020;8:e536-44.

53 Instituto Nacional de Estadistica y Geografía. Encuesta Nacional de la Dinámica Demográfica (ENADID) 2018 [Internet]. Ciudad de México, 2019. Available: https://www.inegi.org.mx/programas/ enadid/2018/

54 Martínez-Mesa J, Werutsky G, Michiels S, et al. Exploring disparities in incidence and mortality rates of breast and gynecologic cancers according to the human development index in the Pan-American region. Public Health 2017;149:81-8.

55 Hassanipour-Azgomi S, Mohammadian-Hafshejani A, Ghoncheh $\mathrm{M}$, et al. Incidence and mortality of prostate cancer and their relationship with the human development index worldwide. Prostate Int 2016;4:118e124.

56 Aldridge RW, Nellums LB, Bartlett S, et al. Global patterns of mortality in international migrants: a systematic review and metaanalysis. Lancet 2018;392:2553-66.

57 Van Hemelrijck WMJ, Rosskamp M, De Schutter H, et al. Cancer risk among individuals of migrant origin in Belgium during the 2000s - Evidence of migration as a 'cancer risk transition'? Soc Sci Med 2021;269:113591.

58 Bray F, Jemal A, Grey N, et al. Global cancer transitions according to the human development index (2008-2030): a population-based study. Lancet Oncol 2012;13:790-801.

59 Siakholak FR, Ghoncheh M, Pakzad R, et al. Epidemiology, incidence and mortality of oral cavity and lips cancer and their relationship with the human development index in the world. Biomed. Res. Ther. 2016;3:872-88.

60 Instituto Nacional de Cancerología. Red Nacional de Registros de Cáncer [Internet]. Registros de cáncer de base poblacional, 2020. Available: https://redcancer.mx/registros

61 Chan J, Polo A, Zubizarreta E, et al. Access to radiotherapy and its association with cancer outcomes in a high-income country: addressing the inequity in Canada. Radiother Oncol 2019;141:48-55.

62 Pervaiz R, Faisal F. Cancer incidence and mortality are associated with human development index and health setups in Africa. J Egypt Natl Canc Inst 2017;29:123-6.

63 Hou J, Walsh PP, Zhang J. The dynamics of human development index. Soc Sci J 2015;52:331-47.

64 IHME. Rethinking development and health: findings from the global burden of disease study, 2016.

65 Murray C, Ezzati M, Flaxman A. Comprehensive systematic analysis of global epidemiology: definitions, methods, simplification of DALYs, and comparative results from the global burden of disease study 2010. Lancet 2012;380:2066-70. 